06

\title{
Высокоскоростная деформация и разрушение стали 15Х2НМФА под действием ударной нагрузки при нормальной и повышенной температурах
}

\author{
(ㄷ Г.И. Канель, ${ }^{1}$ Г.В. Гаркушин, ${ }^{2}$ А.С. СавиныХ, ${ }^{2}$ С.В. Разоренов, ${ }^{2}$ С.А. Атрошенко ${ }^{3}$ \\ ${ }^{1}$ Объединенный Институт высоких температур РАН, \\ 125412 Москва, Россия \\ ${ }^{2}$ Институт проблем химической фризики РАН, \\ 142432 Черноголовка, Московская обл., Россия \\ ${ }^{3}$ Институт проблем машиноведения РАН, \\ 199178 Санкт-Петербург, Россия \\ e-mail: garkushin@ficp.ac.ru
}

Поступило в Редакцию 5 августа 2019 г.

В окончательной редакции 5 августа 2019 г.

Принято к публикации 19 сентября 2019 г.

\begin{abstract}
Представлены результаты регистрации ударно-волновых явлений в стали 15Х2НМФА при комнатной температуре и $504 \pm 5^{\circ} \mathrm{C}$. На основании измерений профилей скорости свободной поверхности определены зависимости сопротивления деформированию и разрушению материала от скорости деформации. Найдено, что сталь 15Х2НМФА характеризуется вдвое более высокой динамической прочностью на растяжение, чем железо, при практически равных значениях динамического предела упругости. С увеличением температуры динамический предел упругости стали падает быстрее, чем в случае железа, в то время как динамическая прочность на разрыв изменяется незначительно.
\end{abstract}

Ключевые слова: корпусная сталь, ударные волны, деформация, температура, динамический предел упругости, откольная прочность.

DOI: $10.21883 / J T F .2020 .03 .48929 .295-19$

\section{Введение}

Стали композиции $\mathrm{Cr}-\mathrm{Ni}-\mathrm{Mo}-\mathrm{V}$ разработаны для корпусов реакторов ВВЭР-1000. Они обладают высокими прочностными свойствами и высокой вязкостью разрушения. Исследование динамических прочностных характеристик стали этого класса стимулируется необходимостью прогнозирования интенсивных ударных воздействий техногенной или террористической природы на конструкции реактора. Имеются также вопросы академического характера относительно влияния температуры и скорости деформации на сопротивление пластическому деформированию и разрушению сплавов и сталей. Первый из них связан с соотношением динамической прочности материала с его динамическим пределом текучести. Хотя во многих случаях материалы с более высокой откольной прочностью (прочностью на растяжение, реализуемой в условиях ударно-волнового нагружения) обладают и более высокими значениями динамического предела упругости, эта корреляция не универсальна. Второй важный вопрос связан с влиянием температуры на сопротивление высокоскоростному деформированию и разрушению. Этот вопрос не столь тривиален, как может показаться.

Исследованиями последних лет установлено, что предел текучести ряда металлов со структурой ГЦК и ГПУ в условиях высокоскоростной деформации может возрастать с увеличением температуры [1-5]. Этот эффект аномального термического упрочнения объясняется большим вкладом фононной вязкости в сопротивление движению дислокаций при высоких скоростях деформации [6]. Для металлов со структурой ОЦК аномальное термическое упрочнение не наблюдалось. Подобных экспериментальных данных для сплавов имеется очень мало и они противоречивы. В экспериментах титановым сплавом [7] наблюдалось падение динамического предела текучести при увеличении температуры, в отличие от титана $[8,9]$, для которого в зависимости от чистоты наблюдалось либо возрастание, либо постоянство напряжения пластического течения при повышении температуры испытаний. В экспериментах с латунью [10] получено возрастание динамического предела текучести, а для отожженных алюминиевых сплавов либо его возрастание [11], либо постоянство [12]. Для жаропрочных сплавов $\mathrm{Ni}-\mathrm{Co}-\mathrm{Fe}$ получены [13] немонотонные зависимости динамического предела текучести от температуры, коррелирующие с немонотонным изменением теплоемкости и связываемые с уравновешением ближнего порядка.

В связи с имеющейся неопределенностью и разнообразием температурных зависимостей сопротивления высокоскоростному деформированию представляет интерес накопление экспериментальных данных и их сопоставление для сталей и сплавов с разными проч- 
ностными свойствами. В настоящей работе представлены результаты исследований динамической прочности конструкционной стали 15Х2НМФА в условиях нагружения импульсами ударного сжатия субмикросекундной длительности при нормальной и повышенной до $500^{\circ} \mathrm{C}$ температурах.

\section{Исследуемый материал}

Примерный химический состав стали по данным производителя НПО „Прометей“, опубликованный, в частности, в работах $[14,15]$, представлен в таблице. Образцы стали 15Х2НМФА были вырезаны из кованой и затем прокатанной обечайки толщиной $350 \mathrm{~mm}$. Материал прошел закалку в воде от $1000-1020^{\circ} \mathrm{C}$ с последующим отпуском при 670-690 ${ }^{\circ} \mathrm{C}$ в воздухе, имел практически изотропную структуру сорбита с размером зерен $34 \pm 4 \mu \mathrm{m}$, предел прочности $740 \mathrm{MPa}$, предел текучести $640 \mathrm{MPa}$, удлинение $22.5 \%$, сужение $80 \%$. Измеренное значение продольной скорости звука составило $5953 \mathrm{~m} / \mathrm{s}$, что практически не отличается от скорости звука в железе. Так как доля легирующих добавок в стали, в общем, невелика, при обработке экспериментальных данных допустимо использовать модули упругости железа.

Заготовки образцов были вырезаны из обечайки лазерной резкой и представляли собой бруски с размерами $22 \times 25 \times 70 \mathrm{~mm}$. Образцы для ударно-волновых исследований толщиной от 0.05 до $4 \mathrm{~mm}$ вырезались из одной заготовки электроэрозионным методом перпендикулярно длинной оси бруска; боковые поверхности образцов представляли собой часть боковой поверхности заготовки. Плоские поверхности образцов после электроэрозионной резки получались параллельными друг другу, достаточно гладкими и нуждались лишь в небольшой полировке.

\section{Постановка экспериментов}

Эксперименты выполнены с применением газовой пушки в качестве генератора импульсов ударного сжатия. Сжатый газ разгонял пустотелый алюминиевый цилиндр, на донышко которого, обращенное к образцу, был наклеен диск из полиметилметакрилата толщиной $5 \mathrm{~mm}$, на который, в свою очередь, наклеен медный ударник. Толщина ударника в зависимости от цели эксперимента варьировалась от 0.2 до $2.5 \mathrm{~mm}$. Подложка из полиметилметакрилата обеспечивала необходимую жесткость конструкции с тем, чтобы предотвратить прогиб ударника в процессе ускорения, и обеспечивала разгрузку ударно-сжатого состояния ударника после выхода на нее ударной волны. Скорость удара составляла 340-360 m/s. Напряжение сжатия за пластической ударной волной в стальном образце при такой скорости удара составляло примерно $6.2 \mathrm{GPa}$. Ствол и пространство вокруг образца вакуумировались.

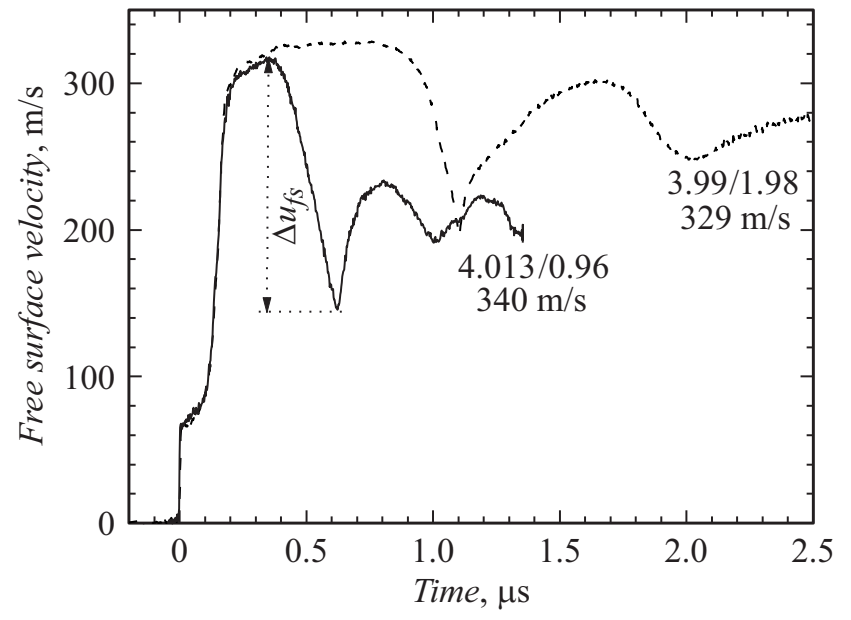

Рис. 1. Профили скорости свободной поверхности образцов стали 15Х2НМФА с номинальной толщиной $4 \mathrm{~mm}$, полученные при ударе медной пластиной толщиной номинально $1 / 2$ и $1 / 4$ от толщины образца. Указаны точные значения толщин образца и ударника, а также скорость удара.

В экспериментах электроконтактными датчиками контролировались скорость и перекос ударника, а лазерным интерферометрическим измерителем VISAR [16] профиль скорости $u_{f s}(t)$ центральной точки свободной тыльной поверхности образца. Временное разрешение на профиле скорости составляло примерно $1 \mathrm{~ns}$. В экспериментах при повышенной температуре нагрев образцов осуществлялся с помощью резистивных нагревателей. Желаемая температура достигалась обычно в течение $10 \mathrm{~min}$ или менее.

\section{Результаты измерений}

На рис. 1 представлены профили скорости свободной поверхности образцов стали 15Х2НМФА толщиной $4 \mathrm{~mm}$, полученные в опытах с ударниками различной толщины. На волновых профилях регистрируется выход на поверхность упругопластической волны ударного сжатия и, после циркуляции волн в ударнике, части волны разрежения. Амплитуда упругого предвестника HEL (Hugoniot Elastic Limit) пропорциональна величине динамического предела упругости [2,17]. Пластическая волна сжатия имеет вполне измеримое время нарастания параметров, что характерно для слабых ударных волн. Нарастание параметров в области между упругой и пластической волнами обусловлено деформационным упрочнением, а также релаксацией напряжений при высокоскоростном деформировании. Небольшой наклон передней части плато скорости между волнами сжатия и разрежения, отчасти, есть также результат релаксации напряжений и, отчасти, следствие многократных ревербераций упругого предвестника между свободной поверхностью и пластической ударной волной [2]. Дли- 
Химический состав (плавочный, mass.\%) стали 15Х2НМФА

\begin{tabular}{c|c|c|c|c|c|c|c|c|c}
\hline $\mathrm{C}$ & $\mathrm{Si}$ & $\mathrm{Mn}$ & $\mathrm{Cr}$ & $\mathrm{Ni}$ & $\mathrm{Mo}$ & $\mathrm{V}$ & $\mathrm{Cu}$ & $\mathrm{S}$ & $\mathrm{P}$ \\
\hline $0.13-0.18$ & $0.17-0.37$ & $0.30-0.60$ & $1.8-2.3$ & $1.0-1.5$ & $0.5-0.7$ & $0.10-0.12$ & $<0.3$ & $<0.02$ & $<0.02$
\end{tabular}

тельность плато скорости определяется временем реверберации волн в ударнике.

После отражения волны сжатия от свободной поверхности внутри плоского образца происходит взаимодействие встречных падающей и отраженной волн разрежения, в результате чего генерируются растягивающие напряжения, и происходит откольное разрушение. Релаксация растягивающих напряжений при разрушении приводит к появлению на профиле скорости свободной поверхности второй волны сжатия - так называемого откольного импульса, в которой скорость поверхности вновь возрастает. Последующие колебания скорости поверхности вызваны многократными отражениями волн между поверхностью откольного разрушения и свободной тыльной поверхностью плоского образца. Средняя скорость поверхности в процессе колебаний на рис. 1 остается практически неизменной, что говорит о том, что к концу первой реверберации откольное разрушение практически завершилось, откольная пластина в ее центральной части полностью отделилась от остальной части образца.

Декремент скорости $\Delta u_{f s}$ перед фронтом откольного импульса пропорционален величине растягивающего напряжения непосредственно перед откольным разрушением - откольной прочности $\sigma_{s p}$. Четко видимое на рис. 1 различие в величинах $\Delta u_{f s}$ для образцов одинаковой толщины в опытах с разными ударниками связано в основном, как будет показано ниже, с искажением волнового профиля вследствие различия в скоростях распространения фронта откольного импульса и падающей волны разрежения перед ним. На профиле скорости свободной поверхности в опыте с ударником толщиной $2 \mathrm{~mm}$ просматривается выделение упругого предвестника в откольном импульсе. Откольный импульс представляет собой волну сжатия, распространяющуюся в растянутом упругопластическом материале. Начальная стадия сжатия в этом случае должна быть упругой и, следовательно, формирование упругого предвестника откольного импульса вполне соответствует ожиданиям.

На рис. 2 представлены результаты серии из трех опытов с образцами стали толщиной $2 \mathrm{~mm}$. Волновые профили качественно подобны показанным на рис. 1. При минимальной толщине ударника и соответственно откольной пластины регистрируется небольшое общее торможение последней в процессе реверберации волн. Дело в том, что величина растягивающего напряжения определяет только условия инициирования разрушения. Для его полного завершения необходимо совершить некоторую работу, на что расходуется часть кинетической энергии откалывающейся пластины. При

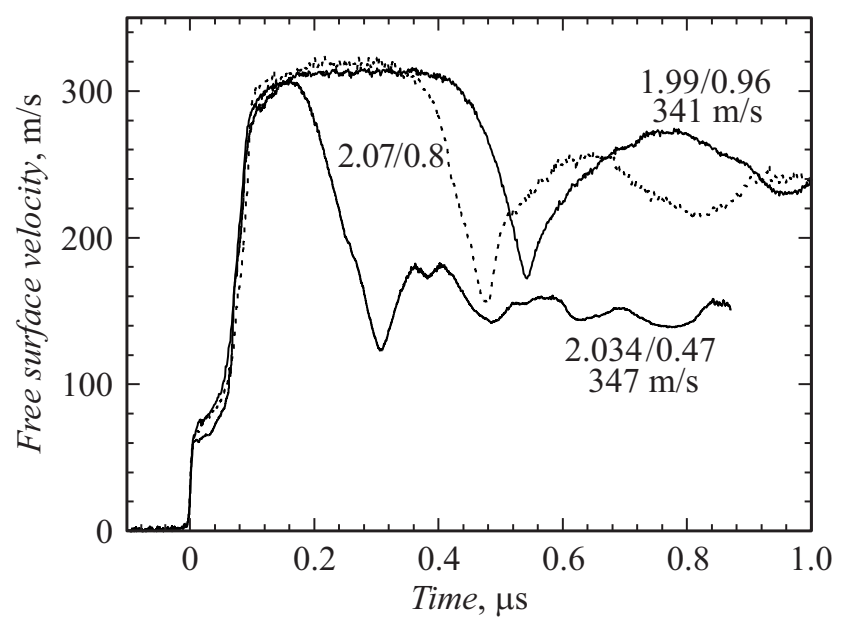

Рис. 2. Профили скорости свободной поверхности образцов стали 15Х2НМФА с номинальной толщиной $2 \mathrm{~mm}$ при использовании медных ударников различной толщины.

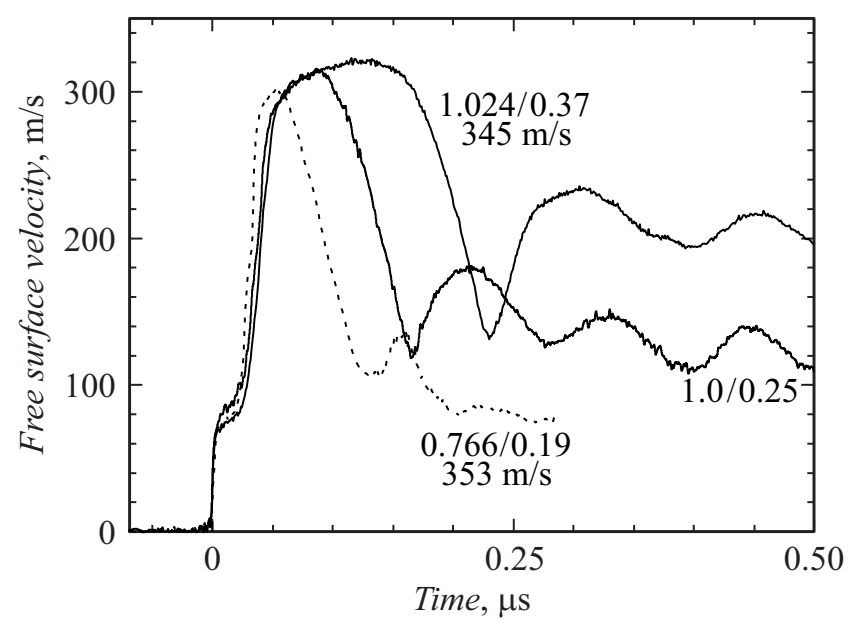

Рис. 3. Профили скорости свободной поверхности образцов стали 15Х2НМФА толщиной $0.77-1 \mathrm{~mm}$, полученные при использовании медных ударников различной толщины.

прочих равных условиях запас кинетической энергии откалывающейся пластины, очевидно, пропорционален ее толщине. Кроме того, близость зоны разрушения к свободной поверхности образца в опыте с тонким ударником ограничивает длительность действия больших растягивающих напряжений, что также приводит к затягиванию процесса откольного разрушения.

На рис. 3 приведены результаты опытов с образцами стали толщиной $0.7-1 \mathrm{~mm}$. Волновые профили подобны обсуждавшимся выше. При малой толщине 


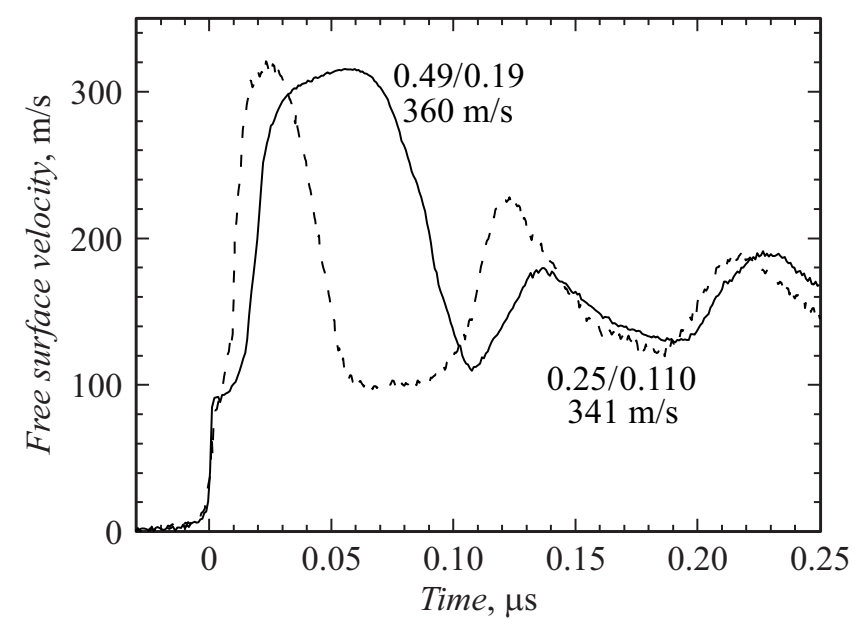

Рис. 4. Профили скорости свободной поверхности образцов стали 15Х2НМФА толщиной $0.25-0.5 \mathrm{~mm}$, полученные при использовании медных ударников различной толщины.

ударника четко выражено затянутое торможение откалывающегося слоя образца. На рис. 4 представлены результаты опытов с образцами толщиной 0.5 и $0.25 \mathrm{~mm}$. В образце толщиной $0.25 \mathrm{~mm}$ откольное разрушение не фиксируется. Разгрузка в данном случае ограничивается не началом разрушения, а условием на поверхности контакта медного ударника с подложкой из полиметилметакрилата. Плато скорости в конце разгрузки примерно на $35 \mathrm{~m} / \mathrm{s}$ превышает параметры, оцененные из соотношения ударных адиабат для удара плексигласовой подложки по стальной преграде, однако эта оценка не учитывает упругопластические свойства стали. Вклад упругопластического поведения материала должен приводить к появлению гистерезиса скорости после цикла ударного сжатия и последующей разгрузки. Декремент скорости $\Delta u_{f s}$ в опыте с полумиллиметровым образцом больше, чем в предыдущих опытах; в эксперименте с образцом толщиной $0.25 \mathrm{~mm}$ он был бы еще больше, если бы разгрузка не была ограничена параметрами удара подложки.

На рис. 5 представлены результаты измерений профилей скорости свободной поверхности образцов стали 15Х2НМФА различной толщины в экспериментах с отколом при температуре $506 \pm 3^{\circ} \mathrm{C}$. Так как эта температура ниже температуры отпуска $\left(670-690^{\circ} \mathrm{C}\right)$, можно считать, что структура материала при нагреве оставалась неизменной. Волновые профили подобны полученным при нормальной температуре содержат все те же особенности и не содержат каких либо новых деталей.

На рис. 6 для образцов толщиной 2 и $4 \mathrm{~mm}$ сопоставляются профили скорости свободной поверхности при комнатной и повышенной температурах. Непосредственно из этого сопоставления видно, что увеличение температуры привело к почти двукратному уменьшению динамического предела упругости и уменьшению ско- рости сжатия в пластической ударной волне, но почти не повлияло на величину декремента скорости $\Delta u_{f s}$ перед отколом и соответственно величину откольной прочности.

При практически равных скоростях удара максимальные значения скорости свободной поверхности при повышенной температуре оказываются более высокими, чем при комнатной температуре. Это расхождение лишь отчасти объясняется различием динамических импедансов $\rho c$ (где $\rho-$ плотность, $c-$ скорость звука, в данном случае - объемная скорость звука $c_{b}$ ) стали при комнатной температуре и при $506^{\circ} \mathrm{C}$. В скорость поверхности после ударного сжатия и разгрузки вносит

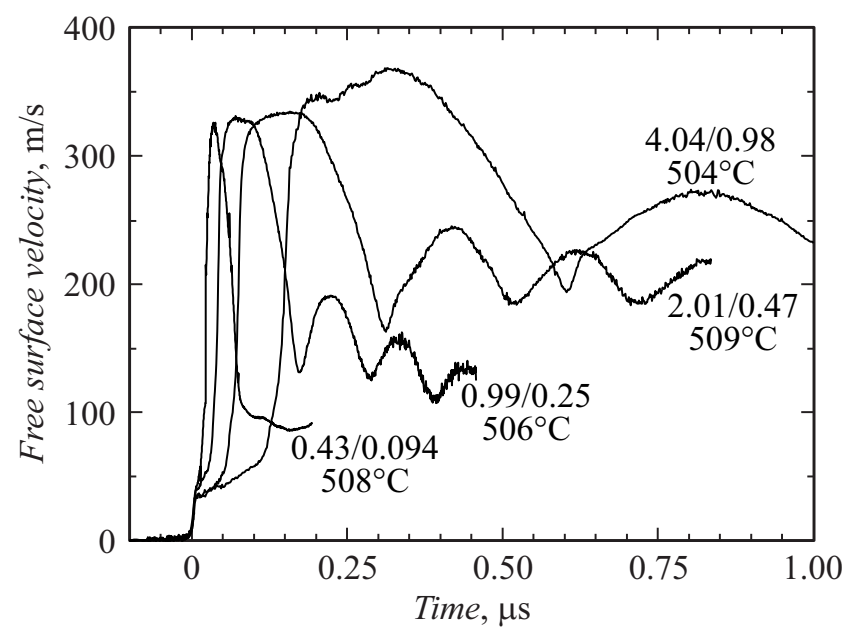

Рис. 5. Профили скорости свободной поверхности образцов стали 15Х2НМФА различной толщины, полученные при повышенной температуре в условиях удара медной пластиной толщиной номинально 1/4 от толщины образца со скоростью $350 \pm 10 \mathrm{~m} / \mathrm{s}$. Указаны значения толщин образца и ударника, а также температура испытания.

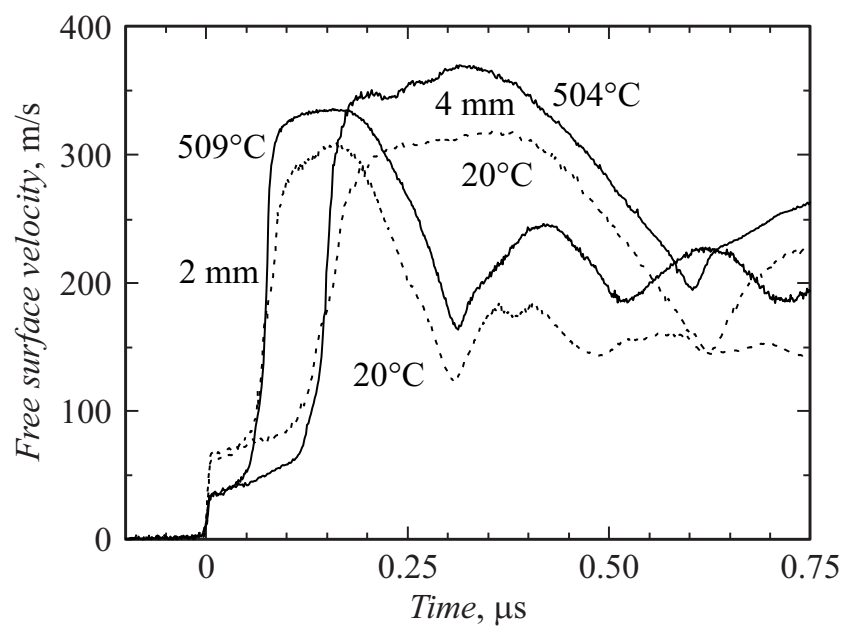

Рис. 6. Сопоставление профилей скорости свободной поверхности образцов стали 15Х2НМФА с номинальной толщиной 2 и $4 \mathrm{~mm}$, измеренных при нормальной (штриховые линии) и повышенной (сплошные линии) температурах. 


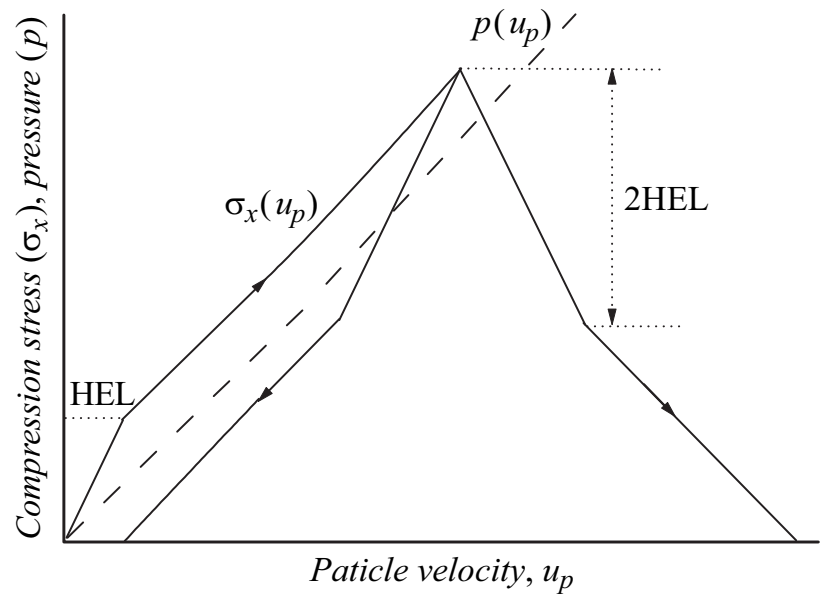

Рис. 7. К пояснению гистерезиса цикла ударного сжатия и последующей разгрузки упругопластического тела.

некоторый вклад гистерезис цикла упругопластического деформирования.

На рис. 7 поясняется образование гистерезиса в цикле одномерного сжатия и разгрузки упругопластического материала. С переходом через предел упругости динамический импеданс изменяется от $\rho c_{l}$ в упругой области (где $c_{l}-$ продольная скорость звука) до $\rho c_{b}$ в области пластичности [2,17]. Соответственно изменяется и наклон траектории изменения состояния. Это имеет место как при сжатии, так и при разгрузке из ударно-сжатого состояния. В результате за волной разрежения, распространяющейся вслед за волной сжатия, вещество имеет остаточную массовую скорость $u_{r}=\frac{\sigma_{H E L}}{\rho}\left(\frac{1}{c_{b}}-\frac{1}{c_{l}}\right)$, а в случае отражения волны сжатия от свободной поверхности последняя приобретает скорость, меньшую на величину $u_{r}$, чем удвоенная массовая скорость ударносжатого вещества [17]. Чем больше величина динамического предела упругости $\sigma_{H E L}$, тем больше отклонение от правила удвоения.

\section{Откольная прочность стали 15Х2НМФА}

Величина откольной прочности определялась по декременту скорости поверхности $\Delta u_{f s}$ при ее спаде от максимума до значения перед фронтом откольного импульса. В линейном (акустическом) приближении:

$$
\sigma_{s p}=\frac{1}{2} \rho_{0} c_{b}\left(\Delta u_{f s}+\delta\right)
$$

где $\delta$ - поправка на искажение профиля скорости вследствие различия скорости фронта откольного импульса и скорости пластической части падающей волны разгрузки перед ним, движущейся с объемной скоростью звука $\left(c_{b}\right)[2,18]$. Значения откольной прочности стали при температуре $506 \pm 3^{\circ} \mathrm{C}$ получены с учетом зависимости скоростей звука и плотности стали от температуры $[19,20]$. Найденные таким способом значения откольной прочности $\sigma_{s p}$ стали $15 \mathrm{X} 2 \mathrm{HМФА}$ представлены на рис. 8 в виде зависимостей от скорости деформирования в падающей волне разрежения. Под скоростью деформирования здесь понимается скорость расширения вешества в волне разрежения, определяемая как

$$
\frac{\dot{V}}{V_{0}}=-\frac{\dot{u}_{f s r}}{2 c_{b}}
$$

где $\dot{u}_{f s r}$ - измеренная скорость спада скорости свободной поверхности испытуемого образца в разгрузочной части импульса ударного сжатия. Показано [21], что начальная скорость роста относительного объема несплошностей при отколе с точностью до постоянного множителя $\sim(2-4)$ равна скорости расширения вещества в волне разгрузки. Следовательно, зависимость величины разрушающего напряжения при отколе от определенной таким образом скорости деформации может быть преобразована в зависимость начальной скорости разрушения от напряжения. Результаты измерений, показанные на рис. 8, аппроксимируются степенными зависимостями

$$
\sigma_{s p}=3.58\left[\left(\dot{V} / V_{0}\right) / \dot{\varepsilon}_{c}\right]^{0.105} \mathrm{GPa}
$$

при комнатной температуре,

$$
\begin{gathered}
\sigma_{s p}=3.2\left[\left(\dot{V} / V_{0}\right) / \dot{\varepsilon}_{c}\right]^{0.105} \mathrm{GPa} \\
\text { при температуре } 506 \pm 3^{\circ} \mathrm{C}, \\
\dot{\varepsilon}_{c}=10^{5} \mathrm{~s}^{-1} .
\end{gathered}
$$

На рис. 8 результаты измерений сопоставляются с полученными ранее данными для АРМКО-железа. Видно, что сталь имеет почти вдвое более высокую откольную прочность, чем железо.

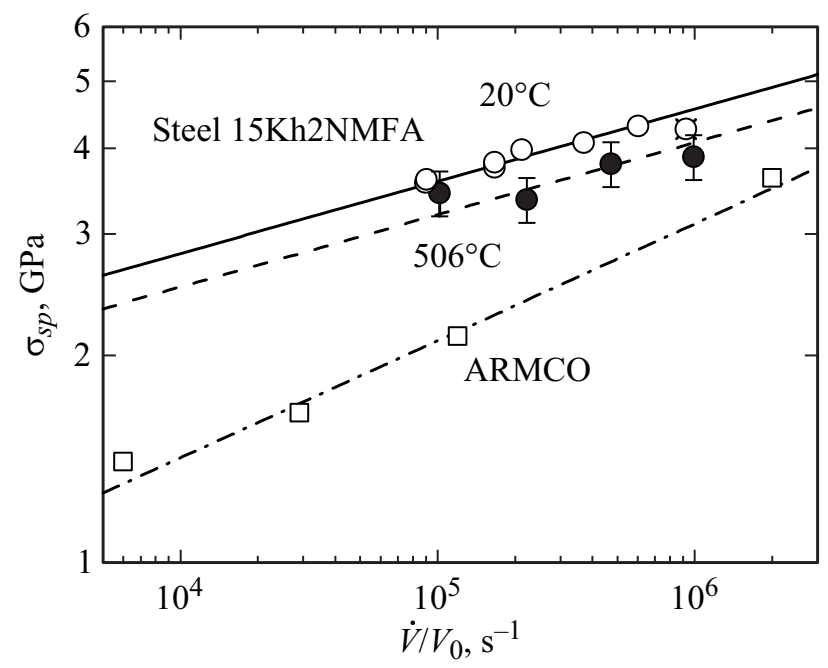

Рис. 8. Результаты измерений откольной прочности стали 15Х2НМФА при нормальной и повышенной температурах в сопоставлении с полученными ранее данными для железа АРМКО. Точки при скорости деформации $\geq 10^{6} \mathrm{~s}^{-1}$ представляют собой оценку снизу: откол в этих опытах не фиксировался. 

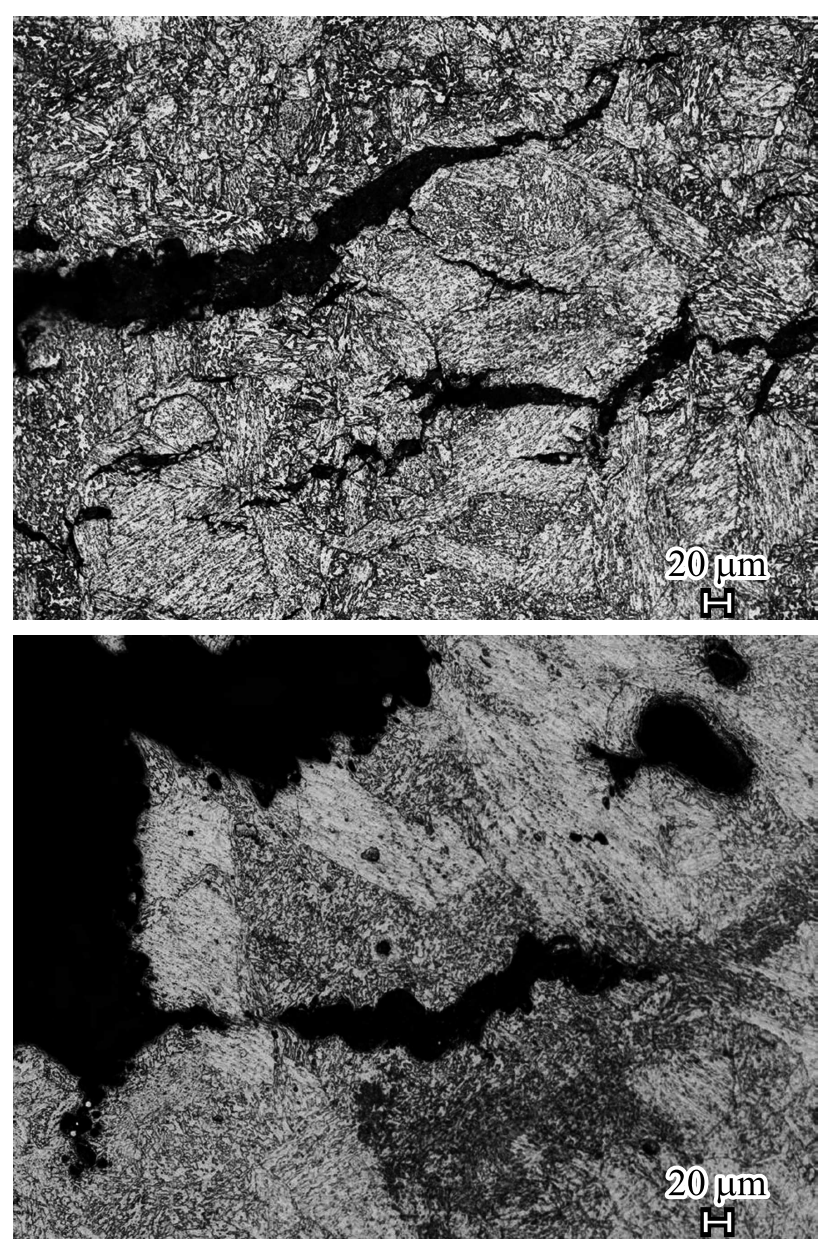

$b$

Рис. 9. Оптические микрофотографии фрагментов откольного разрушения образцов стали толщиной $1 \mathrm{~mm}$ при комнатной температуре $(a)$ и $506 \pm 3^{\circ} \mathrm{C}(b)$.

На рис. 9 показаны оптические микрофотографии фрагментов откольного разрушения стали при комнатной температуре и $506 \pm 3^{\circ} \mathrm{C}$. При комнатной температуре разрушение развивается путем зарождения на карбидах, роста и слияния острых микротрещин. В основном реализуется внутризеренное транскристаллитное растрескивание. В некоторых местах трещина имеет характерный ступенчатый вид и соединяет продольные сдвиги с поперечными разрывами. При высокой температуре трещины затупляются, появляется большое количество округлых пор. Вероятно, благодаря пониженной концентрации напряжений у вершин затупленных трещин материал сохраняет высокую динамическую прочность на разрыв. Заметим для сравнения, что откольное разрушение железа АРМКО происходит путем зарождения и роста большого количества острых прямолинейных трещин [22], что и обусловливает относительно низкое сопротивление разрушению этого материала.

\section{Динамический предел упругости стали 15Х2НМФА}

На рис. 10 сопоставлены фронтальные части профилей скорости свободной поверхности образцов стали различной толщины при нормальной и повышенной температурах. На расстояниях до $0.5-1 \mathrm{~mm}$ регистрируется затухание упругого предвестника, затем в диапазоне 1-4 mm амплитуда предвестника сохраняется практически неизменной. Регистрируемая ширина пластической ударной волны увеличивается по мере распространения; отчасти это связано с переотражениями предвестника между свободной поверхностью и пластической ударной волной [4].

По измеренной величине скачка скорости свободной поверхности во фронте упругого предвестника $u_{H E L}$ определяются значения динамического предела упругости $\sigma_{H E L}$ и динамического предела текучести $\sigma_{t}$, соответ-
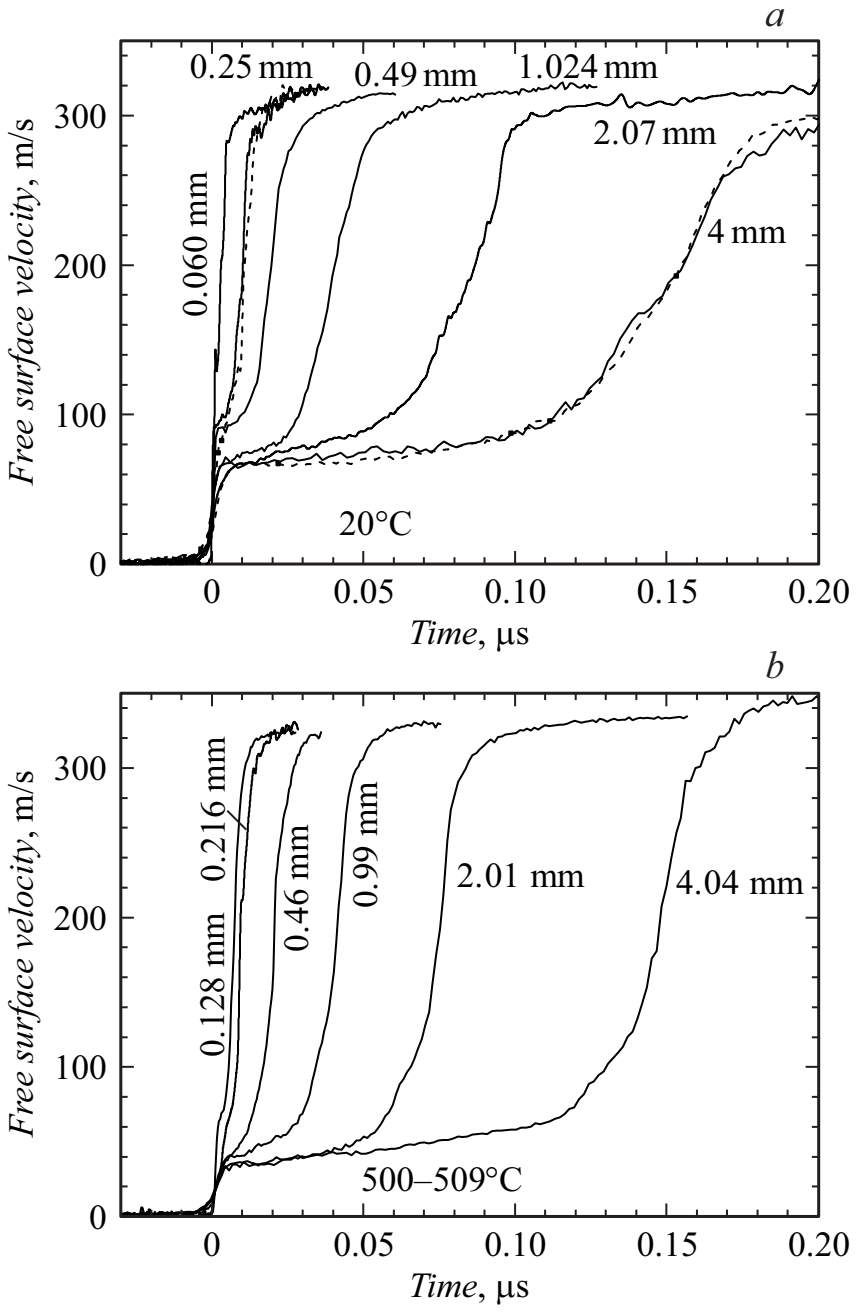

Рис. 10. Фронтальные части профилей скорости свободной поверхности образцов стали 15Х2НМФА различной толщины при нормальной $(a)$ и повышенной $(b)$ температурах. Значения толщины указаны у профилей. 


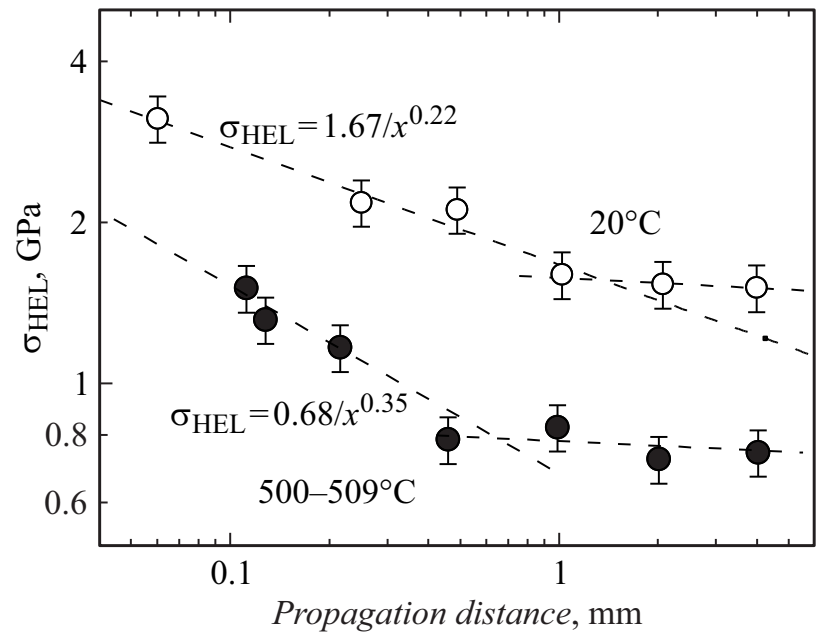

Рис. 11. Зависимость регистрируемых значений динамического предела упругости $\sigma_{H E L}$ и соответствующих значений динамического предела текучести $\sigma_{t}$ стали 15Х2НМФА от пройденного ударной волной расстояния.

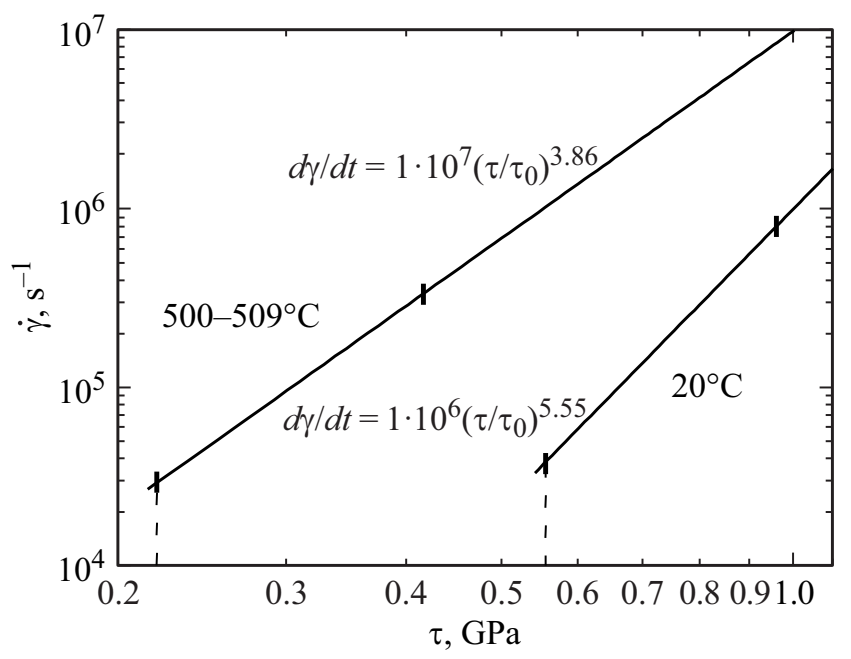

Рис. 12. Зависимости скорости деформации от напряжения на начальном участке распространения ударной волны в стали 15Х2НМФА при нормальной и повышенной температурах. Вертикальные отрезки показывают границы диапазонов экспериментальных данных. Штриховыми линиями ориентировочно показаны оценки зависимостей при умеренных и низких скоростях деформации.

ствующие данному расстоянию распространения волны:

$$
\sigma_{H E L}=\rho c_{l} u_{H E L} / 2, \sigma_{t}=\frac{3}{2} \sigma_{H E L}\left(1-c_{b}^{2} / c_{l}^{2}\right) .
$$

Затухание упругого предвестника волны ударного сжатия вследствие релаксации напряжений связано со скоростью пластической деформации за его фронтом $\dot{\gamma}_{p}=\left(\dot{\varepsilon}_{x}^{p}-\dot{\varepsilon}_{y}^{p}\right) / 2$ соотношением [23]

$$
\left.\frac{d \sigma_{x}}{d h}\right|_{\mathrm{HEL}}=-\frac{4}{3} \frac{G \dot{\gamma}_{p}}{c_{l}},
$$

где $h$ - пройденное волной расстояние, $G$ - модуль сдвига, $c_{l}$ - скорость распространения фронта предвестника, принятая в этом приближении равной продольной скорости звука.

Полученные таким образом зависимости регистрируемых значений динамического предела упругости от пройденного ударной волной расстояния при нормальной и повышенной температурах представлены на рис. 11. Как и для других металлических материалов $[1,2]$, начальный участок эмпирической зависимости аппроксимируется степенной функцией:

$$
\sigma_{H E L}=S\left(h / h_{0}\right)^{-\alpha}
$$

где эмпирические константы $S$ и $\alpha$ при комнатной температуре равны $1.67 \mathrm{GPa}$ и 0.22 соответственно; при температуре $504 \pm 5^{\circ} \mathrm{C} S=0.68 \mathrm{GPa}, \alpha=0.35$; параметр $h_{0}=1 \mathrm{~mm}$. Относительно малая величина показателя $\alpha$ характерна для металлов с объемно-центрированной кубической структурой. При высокой температуре затухание происходит быстрее и переходит в низкоскоростной режим на меньшем расстоянии, чем при комнатной. Любопытно отметить, что экстраполяция показывает пересечение этих зависимостей на расстоянии $1 \mu \mathrm{m}$ при напряжении сжатия в упругом предвестнике около $8 \mathrm{GPa}$.

Эмпирическая зависимость (6) трансформируется в зависимость начальной скорости пластической деформации от напряжения сдвига $\tau$

$$
\dot{\gamma}_{p}=\frac{3}{4}\left(\frac{\tau E^{\prime}}{S G}\right)^{\frac{\alpha+1}{\alpha}} \frac{S \alpha c_{l}}{h_{0} G},
$$

где $E^{\prime}=\rho_{0} c_{l}^{2}-$ модуль продольной упругости, $G-$ модуль сдвига. Рассчитанные с использованием соотношения (7) зависимости начальной скорости сдвиговой деформации от напряжения сдвига при комнатной температуре и при $504 \pm 5^{\circ} \mathrm{C}$ представлены на рис. 12. На

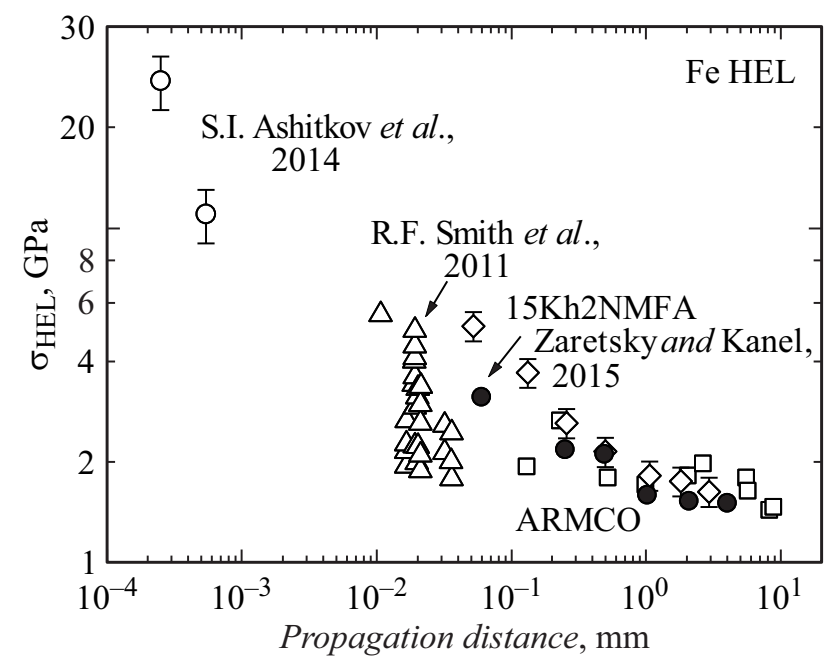

Рис. 13. Сопоставление значений динамического предела упругости стали 15Х2НМФА и железа. 


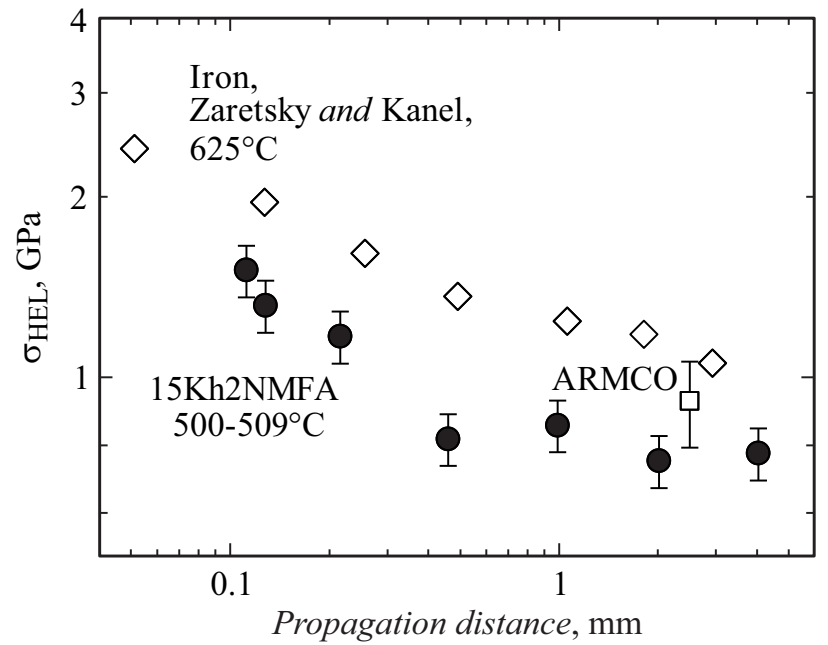

Рис. 14. Сопоставление высокотемпературных значений динамического предела упругости стали 15Х2НМФА, железа с чистотой 99.5\% [25] и железа АРМКО [28].

участке быстрого затухания эти зависимости имеют вид

$$
\begin{gathered}
\dot{\gamma}=10^{6}\left(\tau / \tau_{0}\right)^{5.55} \mathrm{~s}^{-1} \text { при } 20^{\circ} \mathrm{C}, \\
\dot{\gamma}=10^{7}\left(\tau / \tau_{0}\right)^{3.86} \mathrm{~s}^{-1} \text { при } 504^{\circ} \mathrm{C},
\end{gathered}
$$

где $\tau_{0}=1 \mathrm{GPa}$. На расстояниях, больших $1 \mathrm{~mm}$, зависимость резко ослабевает, но затухание должно продолжаться, поскольку напряжение в упругом предвестнике остается высоким, значительно выше предела текучести в нормальных условиях. Зависимость скорости деформации от напряжения на этом участке на графике ориентировочно иллюстрируется штриховыми линиями.

На рис. 13 результаты измерений динамического предела упругости стали $15 \mathrm{X} 2 \mathrm{HМФА} \mathrm{при} \mathrm{комнатной} \mathrm{тем-}$ пературе сопоставляется с полученными ранее [24-28] аналогичными данными для железа. В основном эти данные в пределах разброса совпадают. Более интересно сопоставление значений динамического предела упругости стали и железа при высокой температуре, представленное на рис. 14. Видно, что с увеличением температуры динамический предел упругости стали падает гораздо быстрее, чем это имеет место в случае железа. Вероятно, здесь мы имеем дело с проявлением необычного поведения твердых тел в условиях высокоскоростной деформации [1], когда упрочняющие включения становятся источниками дислокаций, понижающими напряжение пластического течения.

\section{Заключение}

По результатам измерений профилей скорости свободной поверхности образцов стали 15Х2НМФА различной толщины определены зависимости сопротивления деформированию и разрушению материала от скорости деформации и температуры, которые в дальнейшем могут быть использованы при построении математических моделей и определяющих соотношений. Найдено, что при комнатной температуре сталь характеризуется вдвое более высокой динамической прочностью на растяжение, чем железо, при практически равных значениях динамического предела упругости. Поскольку сопротивление росту несплошностей пропорционально пределу текучести материала, различие динамической прочности стали и железа определяется, по-видимому, количеством потенциальных очагов разрушения в этих материалах. Увеличение температуры до $500^{\circ} \mathrm{C}$ привело к практически двукратному понижению динамического предела упругости, но незначительно повлияло на величину динамической прочности на разрыв - откольной прочности. Неожиданным явилось более быстрое, чем это имеет место для железа, падение динамического предела упругости стали с ростом температуры. Вероятно, это является проявлением специфики высоких скоростей деформации, при которых упрочняющие включения могут становиться источниками дислокаций, понижая тем самым сопротивление пластическому деформированию.

\section{Финансирование работы}

Работа выполнена при поддержке Государственной корпорации „Росатом“ с использованием оборудования Московского регионального взрывного центра коллективного пользования РАН.

\section{Конфликт интересов}

Авторы заявляют, что у них нет конфликта интересов.

\section{Список литературы}

[1] Канель Г.И., Зарецкий Е.Б., Разоренов С.В., Аиитков С.И., Фортов В.Е. // УФН. 2017. Т. 187. № 5. С. 525.

[2] Канель Г.И. Ударные волны в физике твердого тела. М.: Физматлит, 2018. 208 c.

[3] Chen L., Swift D.C., Austin R.A., Florando J.N., Hawreliak J., Lazicki A., Saculla M.D., Eakins D., Bernier J.V., Kumar M. // AIP Conf. Proc. 2017. Vol. 793. P. 110008.

[4] Gurrutxaga-Lerma B., Shehadeh M.A., Balint D.S., Dini D., Chen L., Eakins D.E. // Internat. J. Plasticity. 2017. Vol. 96. P. 135.

[5] Shu H., Fu S., Huang X., Pan H., Zhang F., Xie Z., Ye J., Jia G. // J. Appl. Phys. 2014. Vol. 116. P. 033506.

[6] Альшии, В.И., Инденбом В.Л. // УФН. 1975. Т. 115. № 1. C. 3.

[7] Krüger L., Meyer L., Razorenov S.V., Kanel G.I. // Int. J. Impact Eng. 2003. Vol. 28. N 8. P. 877.

[8] Zaretsky E.B. // J. Appl. Phys. 2008. Vol. 104. P. 123505.

[9] Kanel G.I., Razorenov S.V., Garkushin G.V. // J. Appl. Phys. 2016. Vol. 119. P. 185903.

[10] Zaretsky E.B., Kanel G.I. // J. Appl. Phys. 2018. Vol. 124. P. 045902.

[11] Гаркушин Г.В., Разоренов С.В., Канель Г.И. // ФТТ. 2008. Т. 50. Вып. 5. С. 805. 
[12] Разоренов С.В., Канель Г.И., Фортов В.Е. // ФММ. 2003. T. 95. № 1. C. 91.

[13] Zaretsky E.B., Kanel G.I., Razorenov S.V., Baumung K. // Int. J. Impact Eng. 2005. Vol. 31. N 1. P. 41.

[14] Воеводин В.Н., Волчок О.И., Ожигов Л.С., Оковит В.С., Чиркина Л.А. // ВАНТ. 2017. Т. 2. № 108. С. 3.

[15] Хлыбов А.А., Углов А.Л. Определение физикомеханических характеристик материала образцов, подвергаемых радиационному облучению. Труды Нижегородского гос. тех. ун-та им. Р.Е. Алексеева. 2013. T. 1. № 98. C. 220-228.

[16] Barker L.M., Hollenbach R.E. // J. Appl. Phys. 1972. Vol. 43. P. 4669.

[17] Зельдович Я.Б., Райзер Ю.П. Физика ударных волн и высокотемпературных гидродинамических явлений. М.: Наука, 1966. 688 с.

[18] Kanel G.I. // Fat. \& Frac. Eng. Mat. Structure. 1999. Vol. 22. N 11. P. 1011-1019.

[19] Dever D.J. // J. Appl. Phys. 1972. Vol. 43. P. 3293.

[20] Zaretsky E.B. // J. Appl. Phys. 2009. Vol. 106. P. 023510.

[21] Канель Г.И., Разоренов С.В., Уткин А.В., Фортов В.Е. Ударно-волновые явления в конденсированных средах. М.: Янус-К, 1996. 407 с.

[22] Curran D.R., Seaman L., Shockey D.A. // 1987. Vol. 147. N 5-6. P. 253.

[23] Duvall G.E. Propagation of plane shock waves in a stressrelaxing medium. In: Strss Waves in Anelastic Solids. Ed. by H. Kolsky, W. Prager. Berlin: Springer-Verlag, 1964. P. 20.

[24] Канель Г.И., Разоренов С.В., Гаркушин Г.В., Ашитков С.И., Комаров П.С., Агранат М.Б. // ФТТ. 2014. Т. 56. Вып. 8. С. 1518.

[25] Zaretsky E.B., Kanel G.I. // J. Appl. Phys. 2015. Vol. 117. P. 195901.

[26] Ashitkov S.I., Komapov P.S., Agranat M.B., Kanel G.I., Fortov V.E. // J. Phys.: Conf. Ser. 2014. Vol. 500. P. 112006.

[27] Smith R.F., Eggert J.H., Rudd R.E., Swift D.C., Bolme C.A., Collins G.W. // J. Appl. Phys. 2011. Vol. 110. N 12. P. 123515.

[28] Kanel G.I., Razorenov S.V., Fortov V.E. // J. Phys.: Condens. Matter. 2004. Vol. 16. N 14. P. S1007. 